\title{
RECONHECER O TRABALHO DOMÉSTICO: DESAFIOS DE UMA ANÁLISE SOCIOLÓGICA
}

Vanessa R. de la Blétière

Dezembro 2008

WP 으 2008/71

DOCUMENTO DE TRABALHO

WORKI NG PAPER 
Vanessa R. de la Blétière ${ }^{1}$

WP nำ 71/2008

Dezembro de 2008

SUMÁRIO

1. INTRODUÇÃO

3

2. O RECONHECIMENTO SOCIAL DO TRABALHO DOMÉSTICO: ALGUNS FACTORES DE PONDERÇÃO

2.1 A QUESTÃO DO GÉNERO

2.2 A AUSÊNCIA DE PROFISSIONALIZAÇÃO E MOROSIDADE DA REGULAMENTAÇÃO

3. AO ENCONTRO DAS EMOÇÕES...

5. CONCLUSÃO

BIBLIOGRAFIA

${ }^{1}$ Dinâmia / ISCTE-IUL. 


\section{Título: RECONHECER O TRABALHO DOMÉSTICO: DESAFIOS DE UMA ANÁLISE SOCIOLÓGICA}

\section{SUMÁRIO}

O trabalho doméstico remunerado tem sido alvo de diferentes estudos que sublinham particularidades desta actividade e que define a precariedade que lhe é socialmente reconhecida. A preocupação em compreender a origem desta invisibilidade, proveniente da desvalorização social que constrange o trabalho doméstico, frequentemente sublinhada por estudos anteriores, a tentativa de perceber a forma se constrói o reconhecimento social desta actividade e a forma como é interiorizado e projectado por quem executa a actividade são os pontos de partida para análise do reconhecimento social do trabalho doméstico em Portugal. Recorrendo, simultaneamente, a alguns conceitos da sociologia das emoções pretende-se, aqui, levantar algumas questões que irão guiar o estudo intensivo que se pretende realizar, como forma de complementar a análise extensiva do trabalho doméstico ${ }^{2}$.

\footnotetext{
${ }^{2}$ Estudo realizado por uma equipa interdisciplinar do DINÂMIA, Projecto PTDC/JUR/65622/2006 -

“Trabalho Doméstico e Trabalhadores Domésticos: Perspectivas Interdisciplinares e Comparadas” 


\section{INTRODUÇÃO}

Reconhecer o trabalho doméstico introduz o caminho que se pretende levar na análise desta actividade e do papel de "empregada doméstica”. Sendo alvo de estudo por diversos especialistas de diferentes áreas, garantindo, desta forma, a sua interdisciplinaridade enquanto fenómeno social pretende-se estudar o reconhecimento social desta categoria laboral levantando pistas para uma análise emocional do fenómeno em questão. Cruzando dois campos tradicionalmente opostos: a esfera social - mercado de trabalho - e a esfera privada da família - campo de emoções e de sentimentos, escolheu-se a análise sociológica das emoções como forma a complementar a análise transversal do fenómeno do reconhecimento social do trabalho doméstico em Portugal, partindo-se do principio de que a própria interiorização do papel social de empregada doméstica impõe já o reflexo de um fraco reconhecimento social.

O presente workingpaper apenas pretende expor algumas pistas que irão ser seguidas ao longo desta investigação; ser o esboço do caminho que se pretende alcançar e, sobretudo, levantar questões cuja procura de respostas irá traçar o rumo da análise que se pretende realizar.

Desta forma, o primeiro capítulo deste workingpaper apenas discute alguns factores que, necessariamente, devemos ter em conta na análise do reconhecimento social. São factores que caracterizam a actividade laboral em estudo e que delimitam o quadro comum de valores que a distingue das outras actividades laborais. Todos estes aspectos levam-nos a suspeitar de um fraco reconhecimento social implícito nesta actividade e que será discutido, de forma preliminar, o fraco reconhecimento social, as características implícitas a este fenómeno levantam algumas hipóteses que nos levam a desenhar um caminho rumo às emoções a fim de analisar, num todo, o papel social desempenhado, questões que serão levantadas no ultimo capítulo. 


\section{RECONHECIMENTO SOCIAL DO TRABALHO DOMÉSTICO: ALGUNS FACTORES DE PONDERAÇÃO}

\subsection{A questão do género}

Ao estudar a evolução do trabalho doméstico remunerado, verificamos que um dos marcos desta evolução está intimamente ligado ao processo de emancipação da mulher e consequente entrada no mercado de trabalho; factor primordial que reflecte os seus efeitos numa micro e macro estrutura social. Apesar deste marco que transforma as relações familiares, continuamos a assistir ao paradigma da divisão sexual do trabalho socialmente interiorizado que impulsiona o facto um processo de acumulação de tarefas, por parte das mulheres, entre as tarefas domésticas e o mercado de trabalho na esfera social; processo contínuo onde a igualdade entre os géneros não se verifica (Kergoat; 1998) ${ }^{3}$. Assiste-se, assim, a um crescente aumento de infra-estruturas, entre os quais o trabalho doméstico, que pretende contribuir garantir um suporte às alterações sociais da vida quotidiana e familiar.

A procura de "empregadas domésticas” torna-se, desta forma, uma necessidade mais do que um privilégio mas, ainda assim, se, por um lado, assistimos à emancipação de algumas mulheres, por outro, verificamos que o trabalho doméstico continua a ser, maioritariamente, realizado por mulheres. Desta forma, pode-se dizer que o trabalho doméstico contribui para o empowerment de algumas mulheres que, libertas de uma parte dos encargos domésticos, adquirem maior liberdade para se dedicar a outros campos da vida social impulsionando uma formação e vida profissional superiores que influencia a dinâmica da esfera social. Sendo este processo impulsionado pela acção de uma outra mulher, que substitui grande parte das tarefas atribuídas à "mulher doméstica” no seio da sua família, esta irá desempenhar as tarefas num e noutro lar não estará em processo de empowerment dado que a categoria laboral em que se insere é socialmente caracterizada por ser uma categoria de baixo estatuto sócio-económico ${ }^{4}$.

Por continuarmos a assistir ao paradigma da divisão sexual, que tem efeitos práticos no quotidiano das família, a contratação de uma “empregada” no seio familiar não contribui apenas para aliviar a maior parte dos encargos doméstico, maioritariamente realizado pela mulher, como poderá, de igual forma, apaziguar a relação familiar por libertar as pessoas da

\footnotetext{
${ }^{3}$ Kergoat, Danièle, “La division du travail entre les sexes” in Kergoat, Jacques, (1998).

${ }^{4}$ Devemos salvaguardar, apesar disso, a ideia de que nos séculos passados, uma "empregada doméstica” seria considerada uma posição prestigiante no sentido em que sentia ter o privilégio de poder servir o(a) seu(sua) patrão(ao) e estar próximo deste, fazendo parte da sua vida.
} 
responsabilidade das tarefas domésticas que passa a ser tarefa de uma pessoa exterior ao núcleo familiar, podendo evitar, desta forma, diversos conflitos familiares; facto este, aliás, mencionado em alguns discursos proferidos pelos(as) empregadores(as) ${ }^{5}$ entrevistados(as) até ao momento:

[Pergunta: porque resolveram contratar uma empregada doméstica:]

"É pá, essencialmente ter mais tempo pra nós, mais tempo pra nós. E não haver aquela crise quase... quase que uma crise conjugal séria todos os fins de semana: "Não me apetece fazer limpeza", "É pá, mas tem que se, mas tem de ser", e... foi, foi por aí, não é que... não é que ehh só se sempre era uma manhã ou uma tarde, percebes? Ee... o tempo é cada vez mais curto. Ee... em termos de dinheiro não era, não era assim significativo (...)"

(Gustavo, patrão de uma empregada doméstica)

“(...)Agora, acho que a empregada doméstica tem um papel impor [gaguejar] importantíssimo nuuu [hesitação] numa relação, eeh, a dois. Eu acho que evita muitos conflitos. A existência da empregada doméstica evita imensos conflitos entre o casal. (...) Conflitos, discussões, "Porque tu devias ter feito", "Eu é que devia ter feito", se foi ela a fazer não existe, ninguém, ninguém pode fazer porquee tá feito! Nãé? (...) Portanto eu acho que éee muito importante, tem um papel muito importante nesse, nesse âmbito.”

(Maria, patroa de uma empregada doméstica)

Os conflitos familiares, frequentes no que dizem respeito às tarefas do lar, são reflexo de um desajuste face à mudança de valores, sobre a divisão sexual do trabalho, e a prática efectiva da aç̧ão que permanece nos nossos dias.

A diferenciação de papéis de género na sociedade persiste e condiciona, em particular, o grupo das empregadas domésticas (Guerreiro; 2000). No caso português, a interiorização da ligação deste papel ao género feminino manifesta-se na própria categorização oficial desta profissão que está registada na sua forma feminina “Empregada Doméstica - Casas Particulares” (CNP, 1994). Podemos dizer que esta herança da divisão sexual do trabalho poderá ter influenciado, entre outras coisas, a formação do trabalho doméstico remunerado enquanto actividade maioritariamente feminina. Apesar das alterações socioculturais e económicas a que se assiste, a realidade do espaço das tarefas domésticas continua a ser dominado por mulheres, o que se reflecte na esfera social, mercado de trabalho, no caso do trabalho doméstico sendo esta situação

\footnotetext{
${ }^{5}$ Entrevistas individuais e de grupo realizadas em Lisboa e S. Miguel - Açores, no âmbito do Projecto PTDC/JUR/65622/2006 - "Trabalho Doméstico e Trabalhadores Domésticos: Perspectivas Interdisciplinares e Comparadas”, e da Tese de doutoramento Fadas no lar. O reconhecimento do trabalho doméstico. [Dados empíricos por analisar]
} 
legitimada pela própria Classificação Nacional das Profissões onde, maioritariamente, estão expostas profissões no género masculino.

Quando pensamos em igualdade de género no que diz respeito às tarefas domésticas que estão inerentes a esta actividade laboral, verificamos que a própria ideia de se pensar num homem “empregado doméstico” pode levantar alguns problemas no núcleo familiar. Ficou claro, em algumas entrevistas, a resistência social que existe face a homens "empregados domésticos", esta resistência assiste-se não apenas por parte de algumas mulheres empregadas domésticas,

“Não sei, eh eu por mim acho que...acho um bocado esquisito. Acho que isso pronto, é...é assim ajudar a mulher em casa tudo bem, não é? Agora assim...eu acho que não, acho um bocado ridículo mas pronto [risos] eles lá sabem não é? Se gostam, mas eu acho isso um bocado ridículo, acho.”

(Palmira, empregada doméstica, Lisboa)

que, em grande parte dos casos, apoiam esta ideia,

[pergunta... acha que este trabalho deve ser exclusivamente realizado por de mulheres?]

“Não, acho que não, acho que não, acho que até...acho que isso é uma ideia ultrapassada porque ao fim ao cabo ehh eu aceito que hajam homens que...eh...,por exemplo, tenho o meu marido, uma hipótese, o meu marido. O meu marido eh...eu cozinho bem! Mas o meu marido é mais paciente, tem mais paciência pa se esmerar na cozinha. Ahh... e pronto lá está, o meu marido se decidir..., de vez em quando, ehh se ele decidir, sei lá, os vidros da sala, tamos às vezes à janela tá lá o nariz marcado: “Ah isto tá marcado!”, “ah tá, deixó tar!” “Não seja por isso, eu tiro de lá o nariz!”. Lá vai ele com um papelinho, pronto. Não sei se isso mas...lá está, acho que isso não é uma coisa exclusivamente das mulheres, não tem nada a ver só connosco. Criou-se essa ideia mas não, penso que os homens a partir do momento que gostem de o fazer e até são capazes de ser mais perfeitos do que nós, tenham mais paciência.” [Laura, empregada doméstica, Lisboa]

como, de igual forma, por parte de alguns patrões (homens ou mulheres):

\begin{abstract}
“Não, não era igual. Era homem. Não era igual ehh... é pá ehh... há sempre aquela sensação de que um homem é capaz de fazer... fazer... se quiser fazer mal..., percebe? Está mais à vontade, não é? Há sempre essa percepção. Eu, pelo menos, sinto isso. Ehh não me sentiria tão confortável a contratar um homem enquanto... pra este tipo de trabalho. (...) porque se fosse através de uma empresa de prestação de serviços não teria qualquer problema. Mas assim nestes moldes de... de cidadão... estrangeiro [a empregada deste patrão é brasileira] ou, sei lá, mas é um perfeito desconhecido até chegar...

(Gustavo, patrão de uma empregada doméstica)
\end{abstract}

No caso dos patrões, poderá indicar vestígios de alguma herança de uma apropriação familiar; embora bem menos rígida que a definição que nos sugere Marx e Engels (Engels; 1970), esta primeira forma de propriedade que, segundo os autores, identificava uma apropriação do 
homem face à mulher e aos filhos, poderá ser aqui sentida. Por outras palavras, a resistência do homem em colocar outro homem no seio do seu lar, a ocupar das tarefas domésticas e organização do lar, poderá ser visto como uma espécie de risco à estabilidade do seu lar. Por outro lado, algumas patroas sentiam-se incomodadas pelo facto de ser um homem a limpar e cuidar dos objectos íntimos da família, sentindo-se mais confortáveis com o facto de ser uma mulher a fazer determinadas tarefas o que não deixa de identificar a interiorização dos diferentes papéis de género.

Apesar de se saber que existem alguns (poucos) homens "empregados domésticos" não foi possível, até ao momento, encontrar nenhum em Portugal Continental, mas sim nos Açores. Ainda assim, foi fácil perceber, através das entrevistas, que esta categoria laboral não está, de todo, ligada ao perfil masculino mas sim à homossexualidade:

[Pergunta: Acha que os patrões iriam preferir homens empregados domésticos?]

"Só se for aqueles ah... [faz gesto com as mãos para se referir à homossexualidade; risos] só se for aqueles ehhh.... [risos] só se for aqueles..."

[Luísa, empregada doméstica, S. Miguel - Açores]

[A propósito de um empregado doméstico que conheciam...]

Joana: “É gay... também tens ali um que trabalha ali naquelas senhoras dos carrosséis... aquele é!!?

Nádia: Aquele é! É gay!

Joana: Também trabalha de doméstico. Agora...

Nádia: ... faz tudo! Comida, roupas, tudo!

Joana: Agora... o Manelinho também fazia... também é meio... pronto...

Nádia: ...tem arezinhos... agora se ele é, não sei... [risos] mas ele é rafeiro [expressão açoriana] ... é...

VB: E o que é que acham sobre isso? Um homem a exercer esta profissão? Qual é a vossa opinião?

Joana: Eu penso que não faz o serviço como uma mulher!”

[Joana e Nádia, empregadas domésticas, S. Miguel - Açores]

Parte-se do pressuposto de que a questão da (des)igualdade do género, nesta actividade, sendo também descriminada e estigmatizada é apenas um dos factores que obstem esta actividade de uma maior visibilidade social no sentido de um efectivo reconhecimento social (Dubet; 2007). Por outro lado, torna-se pertinente reflectir sobre o caminho a percorrer na procura de uma igualdade de género no trabalho doméstico quando, em países como Portugal, a denominação surge na forma feminina, categorizando à partida a categoria laboral. 


\subsection{A ausência de profissionalização e morosidade da regulamentação}

Outro grande obstáculo ao reconhecimento social do trabalho doméstico, intimamente relacionado com o anterior, parte sem dúvida, dos efeitos da ausência de profissionalização desta actividade. É complexo definir-se o trabalho doméstico enquanto profissão, dada a inexistência de competências (Dias e Pedroso; 2002). O conceito de profissão (Freire, 2004) baseia-se no nível de "qualificação média ou superior” que implica uma formação inicial correspondente ou "qualificações informais de longa aprendizagem"; para além disso, o conceito de profissão irá também abranger a diferenciação e especificidade técnica ou científica adequada que permite ao indivíduo usufruir de um determinado grau de autonomia profissional e assumir determinadas responsabilidades. Para Freire (2004) é também imprescindível que haja um reconhecimento formal, pelas instituições, pelo mercado de trabalho ou pela "prática social”.

Apesar de estar categorizado na Classificação Nacional das Profissões, o trabalho doméstico, suscita algumas reticências quando tido como profissão essencialmente pela ausência de profissionalização, dado que as definições de profissão sublinham um processo profissional formal de aprendizagem. No caso do trabalho doméstico e, apesar de garantir ser um trabalho, maioritariamente, realizado de forma autónoma, sendo atribuídas muitas responsabilidades à pessoa que o executa, a verdade é que a formação profissional é rara dando lugar ao "savoirfaire" que se adquire ao longo do percurso pessoal e dos processos de socialização de que, na sua maioria mulheres, são alvo. No fundo, em termos de execução de tarefas, este trabalho acaba por não sofrer alterações e basicamente abrange as seguintes tarefas: lavagem e tratamento de roupas, limpeza e arrumo da casa, confecção dos alimentos, vigilância e assistência a crianças, pessoas idosas e doentes, jardinagem, tratamento de animais domésticos, execução de serviços de costura e outras actividades consagradas pelos usos e costumes que estejam relacionadas com o $\operatorname{lar}^{6}$ e que são realizadas no lar, o que vem a ser outro obstáculo à classificação desta actividade como profissão.

A ausência de profissionalização desta actividade poderá ser analisada com base nos factores histórico-culturais anteriormente mencionados. O facto de esta actividade ter nascido de um prolongamento de uma actividade tradicionalmente realizada pelas mulheres, no seio da própria família, coloca obstáculos a maior preocupação no desenvolvimento de estratégias que possam potencializar uma profissionalização. Este facto é transmitido pelas próprias empregadas

\footnotetext{
${ }^{6}$ Decreto-Lei no 235/92, de 24 de Outubro.
} 
domésticas ${ }^{7}$ que, de forma geral, interiorizam a sua actividade como sendo um processo “naturalmente aprendido” em casa, que não necessita de intervenções formais de aprendizagem. Apesar de, muitas vezes, considerarem que o trabalho doméstico é um trabalho pouco valorizado e que se subestima o real trabalho e esforço que estão por detrás das tarefas inerentes ao trabalho doméstico, quando se fala de uma profissionalização e das tarefas executadas, não parecem transmitir esta mesma ideia, sublinhando a ideia de "tarefa fácil”, “aprendizagem em casa” ou mesmo “com as patroas” (sublinhando-se, aqui, uma vez mais, o género feminino).

Podemos definir o reconhecimento como operador de uma identidade - no sentido cognitivo das capacidades ou das competências pertencentes aos indivíduos certificando que estes são mesmo os portadores de um operador de distribuição de valor (no sentido evolutivo) sobre estas mesmas capacidades. Neste sentido, o papel social de "empregada doméstica” é apreendido da forma como the foi transmitido, hereditariamente as tarefas são aprendidas, por via informal, através de um processo de socialização. Sendo capacidades interiorizadas por meio de um processo de socialização, assim como o valor associado à prestação de cada indivíduo na sociedade os indivíduos encontram-se dependentes do contexto da troca social organizada, segundo os princípios normativos do reconhecimento recíproco (Honneth; 1995). É este reconhecimento mútuo que irá conduzir o desenvolvimento da aç̧ão laboral na esfera familiar.

A ausência de profissionalização dificulta, assim, a conceptualização sociológica desta actividade enquanto profissão e contribui, por outro lado, para o facto desta actividade permanecer à margem de um maior reconhecimento social. Apesar de haver um certo reconhecimento desta actividade laboral, uma vez que a sociedade reconhece a figura de “empregada doméstica”, a questão do reconhecimento efectivo desta actividade implica o cruzamento de diversos campos onde nem todos, aparentemente, traduzem reunir as condições para alimentar o processo de reconhecimento, como iremos identificar.

Se, no caso das empregadas domésticas, a própria interiorização do seu papel social, transmitido por via do processo de socialização ${ }^{8}$, tende a minimizar a necessidade de haver uma maior formação das suas competências, este será um valor continuamente reflectido socialmente,

\footnotetext{
${ }^{7}$ Entrevistas individuais e de grupo realizadas em Lisboa e S. Miguel - Açores, no âmbito do Projecto PTDC/JUR/65622/2006 - “Trabalho Doméstico e Trabalhadores Domésticos: Perspectivas Interdisciplinares e Comparadas”, e da Tese de doutoramento Fadas no lar. O reconhecimento do trabalho doméstico. [Dados empíricos por analisar]

${ }^{8} \mathrm{E}$, em muitos casos, trata-se de uma actividade laboral "herdada” pela mãe.
} 
tendo efeitos no processo de reconhecimento desta categoria laboral e irá conduzir a reciprocidade deste do mesmo, processo em que as acções individuais ganham um rumo.

Fala-se também de reconhecimento (ou da ausência deste) quando os códigos as regras de trabalho não são aplicadas, por outras palavras, quando o direito não chega a proteger (Dubet; 2007). Apesar desta relação laboral estar definida legalmente enquanto tal, o espaço onde decorre a acção não permite que haja um verdadeiro reconhecimento legal desta actividade. Isto porque se trata da esfera privada da família onde a preservação da sua intimidade é indiscutível. Como já foi possível apurar, a maior parte das empregadas domésticas não têm contrato escrito de trabalho ou, por outras palavras, o trabalho doméstico é conhecido por ser predominantemente realizado de uma forma informal onde a confiança estabelece esta ligação. Dados preliminarmente retirados das entrevistas realizadas identificam que esta condição é, frequentemente, aprovada por ambas as partes e apenas se verificam algumas excepções no caso das empregadas necessitarem de documentos para sua legalização (por exemplo, imigrantes ilegais que pretendem regularizar a sua situação); identifica-se, também, um desconhecimento generalizado, mais acentuado na população portuguesa, da lei em vigor e dos direitos do(a) trabalhador(a). À primeira vista, esta condição pode não ser significativa mas tem consequências práticas no desenvolvimento das actividades e no reconhecimento dos direitos e deveres dos(as) trabalhadores(as), por exemplo: não ser estipulado pausas para refeições:

[Em relação a uma empregada que vai às consultas da entrevistada] “Vai lá... duas ou três vezes por semana só e no fundo esta avo é é é que... que manda, é uma pessoa muito fria ah... e que... que trata a empregada como se fosse ah... com... hmm... uma pessoa que não tem sentimento e que não tem tempo, tem que trabalhar, trabalhar, trabalhar, trabalhar, nunca a propôs de comer! E eu, reparo nisto como médica, ela tem diabetes tem que comer de três em três horas, e tem os diabetes completamente descompensados e uma das queixas ah... ah... ah... repetitivas desta senhora é que não consegue comer porque a patroa nunca lhe diz pa comer. E penso que a patroa não se apercebe sequer que ela não come! [Ela não come porque...] Porque ninguém a convidou pa sentar pa comer! [pausa grande] Ninguém a convidou pa sentar pa comer. Ninguém determinou o horário para comer!” (Lucie, médica de profissão, patroa de uma empregada doméstica)

Para além disso, o trabalho doméstico é um trabalho precário por não haver perspectiva de carreira (Guerreiro; 2000) o que não apenas dificulta a sua concepção enquanto profissão, como também, o seu processo de reconhecimento. Como podemos verificar, ainda com base na categorização descrita na Classificação Nacional das Profissões, a categoria Empregada Doméstica encontra-se inserida no Grande Grupo 9 - Trabalhadores não qualificados, caracterizado por "trabalhadores não qualificados que executam tarefas simples e auxiliares 
para as quais é requerido esforço físico assim como a utilização de ferramentas e processos manuais” (CNP; 1994). Dentro deste grande grupo, as empregadas domésticas ocupam o subgrupo 9.3.1, referente ao "Pessoal de Limpeza, Lavadeiras, engomadores de roupa $e$ trabalhadores similares" sendo, por fim, atribuída a designação de “empregada doméstica Casas Particulares”9.

Apesar do seu aumento progressivo - segundo dados recentes estimam-se cerca de 100 milhões de empregados domésticos em todo o mundo (OIT; 2008) - tem sido longo o processo da sua regulamentação nalguns países, como no caso de Portugal. Exemplo deste fenómeno é a morosidade ${ }^{10}$ da regulamentação efectiva desta actividade laboral que se iniciou com o DecretoLei nº 508/80, de 21 de Outubro e, posteriormente, D.L. 235/92 de 24 de Outubro.

Se verificarmos a evolução do Salário Mínimo em Portugal, identificamos mais um factor de morosidade no que diz respeito a esta actividade sendo que apenas em 2004 ${ }^{11}$ [DL 19/2004 de 20 de Janeiro] e posterior a qualquer outra actividade, até mesmo a agricultura [DL 14 - B/91, de 9 de Janeiro], consegue ser abrangido pelo salário mínimo, mantendo-a à margem de um maior reconhecimento na esfera social. Para além disso, o salário é, por vezes, acordado por ambas as partes (podendo variar entre salário ao dia, à hora, à semana ou ao mês) ou imposto pela pessoa que executa as tarefas (sendo que, através de redes de contactos informais, consegue ter a noção do preço que habitualmente circula no mercado de trabalho).

É, desta forma, na esfera social, que o trabalho doméstico é categorizado e definido enquanto actividade laboral, inserido no mercado através de uma regulamentação específica. A sua legitimação é adquirida através de uma interiorização conceptual da prática desenvolvida; o conceito de reconhecimento encontra-se, assim, intimamente ligado à ordem legal e contribuindo para a mesma, embora não sejam os únicos campos necessários para que se verifique a existência de reconhecimento (Caillé; 2007). O trabalho doméstico, tal como outros campos, ganha, desta forma, um sentido e significado próprio, nos termos da lei e da sua regulamentação, assim como evoca, no cerne da sociedade, toda uma série de simbolismos

\footnotetext{
${ }^{9}$ É fundamental termos em conta que houve algumas alterações, ainda não divulgadas até ao momento da elaboração deste ensaio, relativamente à última versão da CNP.

${ }^{10}$ Gomes, Pedro e de la Blétière, Vanessa (Agosto, 2009), "Trabalho Doméstico: Singularidades de uma

Actividade Precária", in Le Monde Diplomatique, edição portuguesa, II Série, n. ${ }^{0} 34$.

${ }^{11}$ Evolução do Salário Mínimo Nacional de 1974 até 2008.
} 
pertencentes a um quadro de valores socialmente identificáveis que exercem influência na relação funcional, estabelecida na esfera privada da família. 


\section{AO ENCONTRO DAS EMOÇÕES...}

A lei jurídica moderna representa um meio de expressar o reconhecimento de características universais dos indivíduos, esta forma de reconhecimento social exige um intermediário capaz de expressar a característica diferenças características entre os indivíduos através de uma forma universal. Este modo de reconhecimento pode ser identificado especialmente no campo do trabalho, onde a negação de direitos ou exclusão dos mesmos podem ser exemplo de formas de desrespeito. A estima social é também um modo de reconhecimento individualmente perceptível através dos traços pessoais e habilidades que são baseadas em valores comuns - solidariedade (Honneth; 1995). O desaparecimento de relações recíprocas de reconhecimento leva a experiências de desrespeito e humilhação, situações de violação dos direitos frequentemente identificadas por diversos especialistas que analisam as relações laborais no campo do trabalho doméstico, fundamentalmente na área das migrações (Anderson; 2001ª; 2001b; Cohen; 1991).

Um estudo realizado por Cohen ${ }^{12}$ (1991) sobre empregadas domésticas internas, mereceu particular atenção por ter levantado algumas questões pertinentes de serem analisadas com base na análise transversal do conceito de reconhecimento; algumas das principais conclusões revelam a existência de uma regularidade social identificada neste grupo de trabalhadoras, reveladora de estratégias adoptadas como forma de ultrapassar os obstáculos vividos no dia a dia destas mulheres. Seguindo a trajectória que se pretende desenvolver no estudo do reconhecimento social do trabalho doméstico faz sentido analisar estas estratégias, identificadas no referido estudo ${ }^{13}$, como reflexo de uma ausência de reconhecimento social.

Não expondo, novamente, todos os recursos mencionados no estudo realizado por Cohen, centramos a nossa atenção para dois exemplos específicos. Assim, Cohen identifica, para além dos recursos "externos" (como, por exemplo, a necessidade sentida por parte das empregadas domésticas, sobretudo as que trabalham em regime interno, em criar laços sociais, encontrar grupos de identificação exteriores ao espaço laboral onde trabalham, de forma a ultrapassar o carácter solitário desta actividade e a reforçar uma coesão social), diversos recursos "internos" que ajudam a ultrapassar sentimentos socialmente construídos à volta do conceito de "empregada doméstica”:

\footnotetext{
${ }^{12}$ Rina Cohen, (1991), vol. 14, $n^{\circ} 2$.

${ }^{13}$ Estudo referenciado anteriormente, WP n 2008/62, Março de 2008.
} 
Um dos exemplos referidos por esta autora, e identificado nas entrevistas já realizadas em Portugal, na cidade de Lisboa, e nos Açores, na ilha de S. Miguel ${ }^{14}$, parece estar próximos de uma tentativa de colmatar a ausência de reconhecimento social "exterior” ao núcleo familiar: o hábito frequente que os patrões têm de oferecer bens materiais às empregadas domésticas (roupa, comida, prendas), pode significar não apenas a consciência de uma ausência de reconhecimento social ou, por outro lado, da consciencialização face à precariedade característica desta actividade, como também pode evidenciar uma maior preocupação em reconhecer o esforço, a dedicação, o trabalho ou o contributo que esta pessoa tem num lar de que não faz parte. Embora, no estudo de Cohen, o centro da atenção está voltado para a empregada doméstica (demonstrando que este acto de oferecer prendas e outros bens é frequentemente impulsionado por estas e nunca recusado) aqui importa centrar a atenção no que poderá efectivamente significar este acto em termos de reconhecimento social.

Um outro aspecto referido por Cohen está intimamente ligado ao desempenho da actividade laboral por parte da trabalhadora, verificando que numa fase primária de contrato laboral existe um maior esforço e empenho por parte desta trabalhadora, que aposta numa rápida adaptação e aceitação por parte dos patrões (patroas), aç̧ão que diminui ao longo do tempo ao encontrar-se numa posição estável; o que poderá ser, de igual forma, analisado ao admitirmos uma ausência de reconhecimento social, dado que se este reconhecimento existisse efectivamente ou, por outro lado, fosse efectivamente projectado e sentido por parte da trabalhadora, poder-se-ia verificar a inexistência desta atitude dando lugar a uma regularidade na sua dedicação e emprenho face ao trabalho exercido. Mas esta análise será redutora se descontextualizarmos a actividade laboral em causa. Este comportamento poderá ser projectado pela ausência de reconhecimento interpessoal no espaço laboral como, evidentemente, pela ausência de reconhecimento social impulsionado pelas características inerentes à actividade em estudo: uma actividade se perspectiva de carreira poderá impulsionar o sentimento de "estagnação" reflectindo-se na prática.

O que também se poderia dizer face aos pequenos actos (que Cohen caracteriza como estratégias psicológicas) que forma identificados no estudo e que se traduzem em "pequenas

\footnotetext{
${ }^{14}$ Entrevistas individuais e de grupo realizadas em Lisboa e S. Miguel - Açores, no âmbito do Projecto PTDC/JUR/65622/2006 - “Trabalho Doméstico e Trabalhadores Domésticos: Perspectivas Interdisciplinares e Comparadas”, e da Tese de doutoramento Fadas no lar. O reconhecimento do trabalho doméstico. [Dados empíricos por analisar]
} 
vinganças" face aos patrões (exemplo do humor e do gozo, frequentemente assistido ao contarem historias sobre a vida intima e hábitos da família para quem trabalham ${ }^{15}$ ).

Este estudo foi particularmente interessante na procura do conhecimento científico sobre o reconhecimento social. Para além de garantir a abrangência que o próprio conceito de reconhecimento social e da actividade em estudo pressupõem: a esfera intima e privada da família - onde a acção se desenvolve, bem como, a esfera social - que caracteriza e categoriza o trabalho doméstico e os/as seus/suas trabalhadores/as, indica pistas de investigação para um outro domínio que aparece como tema central no estudo que se pretende realizar: as emoções.

Honeth (1995) entende que as relações de reconhecimento recíproco são imprescindíveis à normatividade das relações e ao próprio percurso individual; o reconhecimento é, assim, inerente às diversas manifestações de amor e de relações afectivas, está presente nos valores da liberdade e, sobretudo, da igualdade (instituídas no centro da moral e do direito modernos) e é próprio à estima que pessoas podem manifestar umas às outras. Estes três princípios do reconhecimento afiguram-se imprescindíveis na análise da experiência histórica particular das/os empregadas/os domésticas/os.

O facto de se poder identificar indícios de um fraco reconhecimento social, no domínio da esfera social, e um maior nível de reconhecimento recíproco na relação íntima entre empregador(a)/empregado(a) levanta algumas questões, fundamentalmente ligadas à gestão emocional realizada por quem vive esta actividade laboral que se encontra constantemente confrontado, no seu dia-a-dia, com ambas as situações. Dado que temos indícios de que a própria interiorização do papel social de "empregada doméstica”, bem como a representação deste papel, reflecte este fraco reconhecimento, existe a necessidade de analisar a prática desta relação laboral, numa micro-perspectiva voltada para a sociologia das emoções.

O fraco reconhecimento social do trabalho doméstico na esfera social pode não ser "praticado" no espaço privado da família onde decorre a acção. Podemos verificar algumas práticas que revelam um certo esforço, por parte de alguns patrões, em agir de forma a combater este facto, o que demonstra já a interiorização de um fraco reconhecimento reflectido nas estruturas sociais. Esta realidade pode ser identificada através de estratégias, algumas já anteriormente mencionadas tais como, oferecer prendas ou outros bens que parece já estar inscrito como uma

\footnotetext{
${ }^{15}$ Por vezes ouvidas ao longo das entrevistas de grupo realizadas.
} 
espécie de "costume" socialmente aceite; o que também se torna frequente verificar são os discursos ou acções que pretendem fazer com que a empregada se sinta acolhida como "membro da família” (conseguindo ou não que esta emoção seja, realmente, sentida pela empregada). Dada a natureza das tarefas, que aponta para uma maior intimidade tal como, por vezes, a afectividade mútua que se desenvolve por parte dos agentes envolvidos na acção pode ajudar a ultrapassar o sentimento que um fraco reconhecimento social desta categoria laboral pode provocar ou apenas camuflar esta realidade no quotidiano laboral.

Como vimos, a esfera da vida familiar, envolvida por uma espécie de membrana que preserva a intimidade do quotidiano dos seus membros, representa uma ameaça ao percurso natural de uma eficaz regulamentação directa característica de um trabalho remunerado. O desempenho das tarefas domésticas encontra-se constrangido pelo espaço em que é realizado. Este espaço, “familiar”, considerado como espaço íntimo caracterizado por sentimentos e emoções, evoca um conjunto de práticas, representações, hábitos e estilos de vida diferenciados que irão influenciar diferentes de produção, protegido pelo direito à intimidade da vida familiar. Desta forma, reconhece-se a característica primordial da relação laboral estabelecida: o elevado grau de confiança que exige, bem como, elevada adaptabilidade dos agentes envolvidos (especialmente por parte de quem oferece a sua força de trabalho).

Parte-se de alguns conceitos da sociologia das emoções para aprofundar o conhecimento acerca do reconhecimento social do trabalho doméstico. A questão não será unicamente perceber que emoções podem provir deste tipo de trabalho, mas também perceber de que forma as expressões das emoções podem estar ao serviço do trabalho doméstico como, também, de que forma é apreendido, vivido e sentido no dia-a-dia, o papel de empregada doméstica que pode implicar uma certa discrepância na intensidade entre o reconhecimento social e o reconhecimento mútuo, interpessoal, no âmbito da esfera privada da família; apesar de diferentes níveis de intensidade, é certo que o reconhecimento social abrange estes dois domínios (esfera social e esfera intima de uma relação estabelecida no núcleo familiar), apesar disso, a intensidade do reconhecimento poderá ser vivida de outra forma dado que o espaço social é diferente, mais intimo, podendo conduzir a acções que tendem ultrapassar o sentimento de subordinação naturalmente existente em qualquer relação entre patrão/empregada(o).

O facto do trabalho doméstico cruzar dois campos tradicionalmente opostos leva-nos a ter de seguir uma análise intensiva do reconhecimento social desta actividade laboral em ambos os espaços. A casa particular - campo de emoções, sentimentos, intimidade e privacidade - 
impulsiona novos sentimentos que ultrapassam a simples relação laboral ocorrida na esfera social. Partindo do princípio que a atribuição de reconhecimento não está apenas associada à identificação ou valorização mas também está, e talvez em primeiro lugar, na aprovação e no testemunho da gratidão - reconhecer um indivíduo é conseguir admitir o seu valor e conseguir dar algo em troca (Caillé; 2007) - esta condição pode ser visível no trabalho doméstico através da natureza da sua relação, inevitavelmente traçada pela proximidade com o campo íntimo de uma vida familiar. $\mathrm{O}$ facto de nos apercebermos de que alguns patrões insistem transmitir um maior reconhecimento falando da sua empregada "como se fosse membro da família” sugere a ideia de talvez nem sempre um reconhecimento efectivo mas sim da necessidade de proteger e confortar a "ama dos seus filhos", a "que cuida do seu lar”, a que "limpa as suas coisas”, ou até mesmo a... "guardiã dos seus segredos"; as empregadas domésticas não necessitam de estar na presença dos membros da família para se aperceber da rotina da família, não precisam de ouvir conversas detalhadas para conhecer a rotina e perceber quando existe algo fora do habitual no quotidiano familiar, por mais que esta relação seja desprendida e vista como uma mera relação laboral, a empregada doméstica faz parte, actua e altera o quotidiano da família. Apesar de, por vezes, esta relação demonstrar ser rígida e distante, na realidade, a autonomia que é atribuída à empregada doméstica, hoje em dia, não pode ser analisada como uma estrita e rígida relação de trabalho no sentido legal do termo. As inúmeras tarefas que podem ser atribuídas a uma empregada doméstica, de acordo com a lei portuguesa e caracterização desta actividade laboral, resumem todas as acções praticadas tradicionalmente pela mulher no seio do seu lar; a confiança que é exigida nesta relação passa não apenas pelo cuidado com os objectos íntimos de uma casa particular, o sigilo ou discrição em não comentar os hábitos adquiridos pelos membros de determinada família, como também a extrema responsabilidade de cuidar de pessoas, membros deste núcleo particular, tudo isto numa actividade tipicamente solitária e individual.

Nem sempre esta relação e este esforço, esta gratidão é, de facto, realizada, nem sempre as relações laborais estabelecidas neste contexto misturam-se nos contornos do reconhecimento até porque o falamos de um contrato (escrito ou não) de trabalho mediado por um salário. O que consideramos ser passivo de análise é o facto de mesmo quando existe um reconhecimento efectivo na esfera privada da família, mesmo quando a empregada nos é apresentada como “membro da família” este sentimento parece poder não ser, por parte da empregada, verdadeiramente sentido mas sim gerido de forma a demonstrar algo que seja esperado.

É neste sentido que faz sentido aprofundar alguns conceitos da sociologia das emoções. O conceito de trabalho emocional (Hochschild; 1979), incisivamente estudado em diversos 
domínios do trabalho (sobretudo no sector dos serviços onde o contacto directo com o público é muito frequente, mas também noutras áreas como as do trabalho doméstico), apresenta-se como o processo pelo qual os indivíduos tomam por referência um padrão de sentimento ideal, construído na interacção social, e que conduz à gestão das suas emoções profundas para as adequar às expectativas de outros, mesmo que não o sintam internamente. A gestão emocional é importante no contexto laboral, uma vez que se reflecte na interacção com as pessoas envolvidas na acção, projectando, desta forma, novas emoções e reacções às emoções que são observadas fisicamente.

A dimensão emocional pode proporcionar aos empregadores um controlo sobre as actividades emocionais dos/as empregados/as (sobretudo em serviços de acesso ao público; Hochschild; 1979) realizado através da formação e da supervisão, por exemplo. Esta particularidade poderá não ser observada no trabalho doméstico, também pelo facto da não existir formação e se esta existir ser informal, pelo contrario, considera-se possível que a maioria desta gestão emocional seja concretizada não através de um controlo sob as acções de quem executa a acção (empregada) mas, sobretudo, um auto-controlo mediado pelas expectativas de quem recebe a força de trabalho. Estas expectativas são apreendidas por todos nós, através do processo de socialização, e da nossa capacidade em interiorizar normas sentimentais que nos guiam a acção e que nos impedem de exprimir sentimentos socialmente condenáveis ou desajustados a uma determinada acção social (por exemplo: num funeral é esperado que as pessoas se sintam tristes). Neste caso, a historia do trabalho doméstico remunerado e a própria experiencia ira conduzir a interiorização desta identidade, assim como, serão interiorizadas as regras emocionais subjacentes a esta identidade.

Para Hochschild (1979), trabalho emocional é o acto de tentar alterar, em qualidade ou quantidade, uma emoção ou um sentimento. Trabalhar uma emoção ou sentimento é o equivalente ao acto de gerir de uma emoção ou de realizar um acto profundo "deep acting”. O trabalho emocional refere-se sempre ao esforço em si (o acto de tentar) e não ao resultado o qual pode ou não ser satisfatório. O trabalho emocional pode assim, segundo a autora, ser realizado de forma cognitiva (tentativa de alterar imagens, pensamentos ou ideias com o objectivo de alterar os sentimentos que lhes estão associados), de forma corporal (tentativa de alterar somáticas ou outros sintomas emocionais físicos como, por exemplo, tentar respirar mais devagar ou tentar não tremer) e de forma expressiva (tentativa de alterar gestos expressivos com o objectivo de alterar sentimentos internos, por exemplo, tentar rir ou chorar); embora sejam distintas, as três técnicas podem aparecer em simultâneo na mesma acção. 
No trabalho doméstico esta gestão emocional pode estar abafada pela própria invisibilidade que caracteriza este tipo de actividade laboral assim como quem a pratica. Esta invisibilidade é tida não apenas pelas características inerentes a esta profissão, que foram anteriormente referidas estando intimamente ligada ao fraco reconhecimento social, como a própria actividade em si e seu produto final - que actua directamente no núcleo familiar - acabam por estar circunscritos à desvalorização que se instituiu socialmente com a divisão sexual do trabalho; o trabalho doméstico é frequentemente visível apenas quando não está feito ou quando se encontra mal feito (Dusset; 1997). Para além disso, apesar da estreita ligação que se pode desenvolver e da gratidão que poderá ser demonstrada nesta relação não se pode deixar de evidenciar o facto de estarmos perante uma relação de trabalho em que a empregada é contratada para realizar um serviço, sendo esta subordinada ao seu(sua) patrão(patroa). Esta relação pode, em certos casos, tender para acentuar a desigualdade existente mas mesmo que não haja esta acentuação, o sentimento de subordinação existe. Muitas vezes, a empregada doméstica deixa a sua própria casa e sua própria família para tomar conta, limpar e cuidar do lar de outra pessoa, regressar a casa, depois de um dia de trabalho, e realizar, muito provavelmente, o mesmo tipo de tarefas na sua própria casa. Quando as desigualdades são excessivas, os indivíduos falam sobretudo de ausência de reconhecimento, mais do que desigualdades no sentido estrito da palavra (Dubet; 2007).

Ao longo do estudo de campo realizado até ao momento, foi possível encontrar alguns fragmentos que levantam algumas hipóteses pertinentes no estudo das emoções no trabalho doméstico. Os pequenos actos que podem ser realizados por parte de alguns patrões na tentativa de demonstrar gratidão e, até, uma certa "igualdade” podem nunca ser, efectivamente, sentidos pela empregada; alguns relatos ouvidos no estudo de campo realizado até aqui levantam algumas questões pertinentes neste sentido, por exemplo, o facto de se sentir à vontade ou não para comer com os patrões à mesa mesmo quando convidada para isso. Este exemplo aparece frequentemente nos discursos; apesar de se sentirem "acolhidas" quando os patrões convidam a almoçar ou jantar com eles, o sentimento de subordinação continua a existir, predominantemente através do habitus interiorizado que distingue os actores envolvidos na ação - o receio de não saber como comer, de não saber como se comportar aparentem como motivos suficientemente fortes para sentir o tal desconforto, motivos que permanecem independentemente da intimidade da relação e da longitude da mesma.

ISCTE - INSTITUTO SUPERIOR DE CIÊNCIAS DO TRABALHO E DA EMPRESA 
O que parece também projectar esta gestão emocional é a necessidade de esconder determinados sentimentos (tristeza, descontentamento, dor física, preocupações com a sua própria família etc.) ao longo do dia-a-dia laboral; se existe uma relação de amizade, em que muitas vezes são conselheiras dos seus patrões, esta relação parece não ser totalmente equilibrada parecendo haver uma interiorização de que o papel da empregada é também, necessariamente, o de saber ouvir e comentar quando lhe for dada a autorização para isso; desta forma, os seus próprios sentimentos, as suas preocupações são, por vezes, omitidas e disfarçadas com um sorriso ou um “está tudo bem” pouco convicente.

Estes pequenos fragmentos tidos em conta ainda de forma preliminar indicam o caminho de um trabalho emocional que parece ser fortemente influenciado pelo fraco reconhecimento social e interiorização de um sentimento de desvalorização, pequenos aspectos como o facto de algumas empregadas domésticas ficarem admiradas por querermos realizar um estudo sobre a sua actividade laboral já demonstra um pouco como a interiorização de uma ausência de reconhecimento é projectada.

Todos estes aspectos inerentes ao trabalho doméstico parecem sugerir a presença inevitável de um maior esforço emocional na gestão emocional inerente ao papel social de empregada doméstica; uma gestão que implica o balanço de quem executa um trabalho que se desenvolve na esfera privada da família e se constitui na esfera social, através de um quadro normativo de valores.

O trabalho de campo realizado até aqui apenas esboça algumas hipóteses que poderão guiar a nossa análise, a caminho das emoções; apesar disso, o caminho ainda é longo e os dados não tratados ainda apenas nos podem servir de pistas para o desenvolvimento do estudo da relação laboral estabelecida neste campo particular e, especificamente, do papel social de empregada doméstica. 


\section{CONCLUSÃO}

O trabalho doméstico, actividade em constante evolução ao longo dos anos, tem suscitado o interesse de alguns especialistas de diferentes áreas. Estudos internacionais focam essencialmente os problemas que estão por detrás de uma actividade precária cuja regulamentação se encontra afectada pela preservação da intimidade do espaço privado em causa - núcleo familiar. Algumas iniciativas têm sido iniciadas com o objectivo de melhorar as condições de vida destes(as) trabalhadores(as), com o intuito de caminhar para um "trabalho doméstico digno” (OIT; 2008).

A preocupação que nos suscita o reconhecimento social do trabalho doméstico surge justamente pela necessidade de melhor compreender a origem de uma desvalorização social e invisibilidade tão frequentemente mencionada em trabalhos anteriores, assim como, perceber de que forma este reconhecimento (ou ausência dele) é interiorizado através do papel social de "empregada doméstica”, de que forma são geridas as emoções entre a desvalorização social e a eventual tentativa de a combater no espaço familiar. Compreender de que forma quem executa estas tarefas apreende a ausência de reconhecimento e se promove, mesmo que de forma inconsciente, a mesma.

No conjunto, tenta analisar de forma intensiva o papel social de empregada doméstica, apreendendo os seus efeitos não apenas na esfera privada da família, no seu próprio desempenho, como também na esfera social e na construção dos significados e categorizações que estão inerentes a esta actividade laboral. 


\section{BIBLIOGRAFIA}

ANDERSON, Bridgest, (2001a), "Different roots in common ground: Transnationalism and migrant domestic workers in London” in Journal of Ethnic \& Migration Studies, Vol. 27 , nº4, p673-683, UBSCO.

ANDERSON, Bridget, (2001b), "Just another Job? Paying for domestic work”, in Gender \& Development, vol. 9, ${ }^{\circ}$ 1, pp. 25-33, UBSCO.

CHABAUD-RYCHTER, Danielle, Dominique Fougeyrollas-Schwebel e Françoise Sonthonnax, (1985), Espace et Temps du Travail Domestique, Méridiens, Paris.

CLARKE, Mary P., (2002), "Domestic work, joy or pain? Problems and solution of the workers”, in Social and Economic Studies, 51: 4.

COHEN, Rina, (1991) "Women of Color in White Households: Coping Strategies of Live-in Domestic Workers.” Qualitative Sociology, Vol. 14 Issue 2, p197, UBSCO.

COLE, Jeffrey, (2006), "Domestic work life and immigration in Sicily”, Journal of Modern Italian Studies, 11:1, 22-36, UBSCO.

COLE, Jeffrey and Sally Booth. 2006. "Domestic Work, Family Life, and Immigration in Sicily." Journal of Modern Italian Studies 11(1): 22-36, UBSCO.

DIAS, J. e Pedroso, J. (2002), “As profissões juridicas entre a crise e a renovação: o impacto do

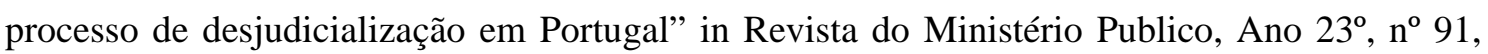
pp. $11-54$.

DUBET, F. (2007), “Injustices et reconnaissance”, in CAILLÉ, Alain (dir.), (2007), La quête de reconnaissance, nouveau phénomène social total, Paris : la Découverte.

DUSSUET, A. (1997), Logiques domestiques, essai sur les représentations du travail domestique chez les femmes actives de milieu populaire, Paris, L'Harmattan. 
DUSSUET, A. (1999), “Les Logiques Domestiques contre les femmes”, in Les Parcours de vies des femmes - Travail, Famille et Représentations Publiques, Paris, L’Harmattan.

DEVAULT, M., (1999), “Comfort and Struggle: Emotion work in Family Life” in The ANNALS of the American Academy of Political and Social Science; 561; 52

ENGELS, F. (1970), A Origem da Família da Propriedade Privada e do Estado, Lisboa: Presença.

FREIRE, João (org.) (2004), Associações Profissionais em Portugal, Oeiras, Celta

GUERREIRO, Maria das Dores, Pereira, Inês (2006), Responsabilidade social das empresas, igualdade e conciliação trabalho-família : experiências do prémio igualdade é qualidade, Lisboa : Comissão para a Igualdade no Trabalho e na Emprego.

GUERREIRO, Maria das Dores, Pedro Abrantes. (2004), Transições incertas: os jovens perante o trabalho e a família, Lisboa : Direcção Geral de Estudos, Estatística e Planeamento.

HOCHSCHILD, Arlie (1979), "Emotion work, Feeling Rules, and Social Structure” in The American Journal of Sociology, Vol. 85, No.3, pp. 551-575

HOCHSCHILD, A. e Ehrenreich, B. (2003), Global Woman: Nannies, Maids, and Sex Workers in the new economy, New York: Metropolitan Books.

HONNETH, A. (1995), The Struggle for Recognition, The moral Grammar of Social Conflicts, UK: Polity Press.

INTERNATIONAL LABOUR ORGANIZATION, (2008), Decent work for domestic workers, (IV item of the Agenda, ILC, $99^{\text {th }}$ Session), Geneva.

KERGOAT, Danièle, "La division du travail entre les sexes” in Kergoat, Jacques, (1998), Le Monde du Travail, Paris, la découverte .

KOUSHA, M. (1995), “African American private household workers, white employees and children.” in International journal of Sociology, 25, 67-89. 
ROLLINS, J. (1985), Between women: domestics and their employers, Philadelphia: Template University Press, UBSCO. 